\title{
Jogos lúdicos como ferramenta avaliativa no ensino de Ciências
}

\author{
Bianca Ferreira Neves \\ Universidade Federal do Amazonas - UFAM, Brasil \\ Felipe Lourenço Albuquerque \\ Universidade Federal do Amazonas - UFAM, Brasil \\ Klenicy Kazumy de Lima Yamaguch \\ Universidade Federal do Amazonas - UFAM, Brasil \\ Apoio e financiamento: Coordenação de Aperfeiçoamento \\ de Pessoal de Nível Superior - CAPES
}

\section{RESUMO}

A ludicidade no ensino vem sendo utilizada como uma ferramenta eficiente para unir o interesse, a motivação e o aprendizado dos discentes. Este artigo aborda uma didática de intervenção lúdica como atividade avaliativa no ensino de ciências em uma escola no interior do Amazonas. A metodologia utilizada consistiu em uma abordagem qualitativa, descritiva e exploratória desenvolvida por acadêmicos do curso de ciências, participantes do Programa Residência Pedagógica. Após a aula de revisão do bimestre letivo, foram aplicados três jogos: Quiz, Trilha do Conhecimento e Pirâmide de Alimentos, com perguntas objetivas e de múltipla escolha. Como critérios de avaliação, foram considerados a participação, o comprometimento, conhecimento teórico e o trabalho em grupo. $\mathrm{O}$ uso de atividades lúdicas como avaliação demonstrou ser uma boa ferramenta para analisar o desempenho e a participação dos discentes, além de despertar o interesse e o cooperativismo entre as equipes. Assim, pôde-se evidenciar a contribuição da ludicidade como estratégia metodológica na formação e desenvolvimento dos discentes.

PALAVRAS-CHAVE: Residência Pedagógica. Ludicidade. Amazonas. Avaliação.

\section{LUDIC ACTIVITIES AS EVALUATIVE TOOL IN SCIENCE TEACHING}

\begin{abstract}
Ludic activities in teaching have been used as an efficient tool to join interest, motivation and student learning. This article aims to show a didactic use of ludic intervention as an evaluative activity in Science subject in the countryside school of Amazonas. The methodology was qualitative, descriptive and exploratory approach developed by undergraduate students participating in the Pedagogical Residency Program. After the lecture review class, three games were applied: Quiz, knowledge trail and food pyramid, with objective questions and multiple choice. As evaluation criteria were participation, commitment, theoretical knowledge and group work. The use of ludic activities demonstrated a good performance and participation of the students, with interest and cooperativism among the teams. It is possible to highlight the contribution of ludic as a didatic strategy in the training and development of students.
\end{abstract}


KEYWORDS: Pedagogical Residence. Ludicity. Amazon Region. Evaluation.

\section{ACTIVIDADES LÚDICAS COMO TÉCNICA DE EVALUACIÓN EN LA ENSEÑANZA DE LAS CIENCIAS}

\section{RESUMEN}

Las actividades lúdicas en la enseñanza se han utilizado como una herramienta eficaz para el interés, la motivación y el aprendizaje de los studiantes. Este artículo tiene como objetivo mostrar un uso didáctico de la intervención lúdica como actividad evaluativa en la asignatura de Ciencias en la escuela de Amazonas. La metodología fue un enfoque cualitativo, descriptivo y exploratorio desarrollado por estudiantes de pregrado en Ciencias, participantes del Programa de Residencia Pedagógica. Tras la clase de repaso magistral, se aplicaron tres juegos: Quiz, Ruta de Conocimiento y Pirámide Alimenticia, con preguntas objetivas y opción múltiple. Como criterios de evaluación fueron la participación, el compromiso, los conocimientos teóricos y el trabajo en grupo. El uso de actividades lúdicas demostró un buen desempeño y participación de los estudiantes, con interés y cooperativismo entre los equipos. Cabe destacar el aporte de lo lúdico como estrategia didáctica en la formación y desarrollo de los estudiantes.

PALABRAS CLAVE: Residencia Pedagógica. Ludicidad. Amazonas. Evaluación.

\section{INTRODUÇÃO}

O ensino de ciências no século XXI é um desafio para os profissionais docentes, sendo necessário desenvolver técnicas que se demonstrem atrativas para os educandos, objetivando uma aprendizagem significativa e eficiente (SILVA; MORADILLO, 2020, REZENDE, 2002). Nem sempre os alunos conseguem interligar o que aprendem com a prática vivenciada no cotidiano e com os assuntos de seu interesse.

A aprendizagem não deve ser algo mecânico em que há apenas transmissão de conteúdos teóricos sem que estes sejam aplicados à realidade do aluno. De acordo com a Base Nacional Curricular Comum Curricular (BNCC), de 2018, o ensino deve possibilitar o desenvolvimento das competências e habilidades dos discentes de interferirem em seu meio em prol do bem-estar social, contribuindo para a formação do indivíduo em sua forma plena (BRASIL, 2018). Quando isso não acontece, o que se observa são alunos desinteressados e com pouca motivação (MENDES et al., 2019; PAIS et al., 2019).

Estratégias didáticas vêm sendo propostas como alternativa para tornar o conteúdo teórico mais plausível, motivador e atrativo, despertando o interesse e a curiosidade dos discentes. Entre elas, tem-se as atividades lúdicas como metodologias capazes de contribuir para a aprendizagem nos diferentes níveis escolares, desde a educação infantil até o ensino universitário (PAIS et al., 2019; MENDES et al., 2019). 
Nesse sentido, este artigo objetiva apresentar a execução de um projeto de intervenção realizado pelos acadêmicos de licenciatura de Ciências: Biologia e Química do Programa Residência Pedagógica em uma escola pública no interior do Amazonas, buscando utilizar uma didática de intervenção lúdica como atividade avaliativa no ensino de Ciências. Pretende-se com isso, contribuir com as pesquisas e discussões sobre as possibilidades de técnicas diferenciadas para avaliar o aprendizado dos discentes.

\section{LUDICIDADE E O ENSINO DE CIÊNCIAS}

O uso de atividade lúdica é reportado por diversos teóricos que buscam explicar o papel que essas ferramentas apresentam para o desenvolvimento social e cognitivo dos indivíduos. Na teoria de Vigotski é demonstrado como a ludicidade é capaz de contribuir com uma inteligência hipotético-dedutiva e psicológica dos sujeitos (VIGOTSKI, 2003).

Para Kishimoto (2001), o lúdico é uma forma de interação com o meio, desenvolvendo habilidades cognitivas relacionadas ao saber, desenvolvimento cultural, interpessoal, social e individual. Assim, o ensino aplicado utilizando técnicas lúdicas contribui com uma aprendizagem colaborativa de saberes, com interação interpessoal e desenvolvimento de trabalho em grupo e capacidade de liderança. Essa é uma possibilidade real que vem sendo utilizada com êxito nas diferentes disciplinas escolares.

Na teoria da aprendizagem significativa, Ausubel (1982) afirma que é necessário que ocorra uma relação entre o que individuo sabe, e o conhecimento que pretende ser obtido. Portanto ao considerar os conteúdos ministrados e o uso de atividades complementares, contribui-se para que o conhecimento possa ser mais be compreendido e assimilado. Corroborando isso, Yamamoto e Valentoza (2018) afirmam que a tendência a aprender com o brincar é uma condição biológica dos primatas e por meio desse tipo de aprendizagem, é possível aproveitar as potencialidades dos recursos naturais em prol do conhecimento.

Ferro e Viel (2019) propõem que o lúdico é a forma que o indivíduo aprende e se desenvolve como ser social, percebendo e assimilando os conteúdos de forma motivacional e em busca de mais conhecimento, estando associado ao que na prática complementa seu anseio. Baseado nisso, espera-se que seja possível desenvolver ferramentas necessárias para oportunizar o aprendizado com o uso de jogos, experimentação utilizando reações perceptíveis macroscopicamente, gincanas e outras ferramentas didáticas. Para tanto, pesquisas na área de ensino de Ciências vêm sendo publicadas utilizando o lúdico em diferentes conteúdos.

Segundo Soares (2016), além da aprendizagem propriamente dita, as atividades lúdicas melhoram a relação professor/aluno, fazendo com que ocorra o desenvolvimento de potenciais 
e oportunidade de obtenção de informações de forma conjunta. Ressalta-se que o uso de jogos em sala de aula deve sempre estar associado a um objetivo e contemplar um planejamento prévio do docente, tendo como meta explorar os conhecimentos e ir além de um momento de descontração. É importante lembrar que o jogo pode ser considerado educativo quando mantém um equilíbrio entre duas funções: a lúdica e a educativa (CUNHA, 2012). Dessa forma, devese evidenciar que a finalidade do jogo é uma ferramenta que irá auxiliar na aprendizagem.

\title{
3 AVALIAÇÃO NO ENSINO DE CIÊNCIAS
}

As avaliações escolares são mecanismos utilizados para verificar o desempenho dos discentes relacionados ao aprendizado de conteúdos estudados nos ambientes de ensino (CHUEIRI, 2008).

Segundo Oliveira, Barroso e Holanda (2020, p.14):

\begin{abstract}
A avaliação é um procedimento relevante no cotidiano escolar, viabilizando colaborar consideravelmente para a aprendizagem do aluno e para, sempre que indispensável, a reestruturando do trabalho docente. No entanto, vezes por outra é disposta de forma automática e classificatória, com o propósito do aluno reprisar as informações, sem alcançar o que seja imprescindível e o que se institui com relação ao conteúdo com a vida cotidiana.
\end{abstract}

No ensino de Ciências, verifica-se que a avaliação é vista apenas como mais uma tarefa burocrática assumida por alunos e professores, onde o modelo tradicional com ênfase na classificação é predominantemente utilizado. Para Alípio e Galieta $(2018$, p. 67) "a avaliação assume um caráter meramente classificatório e pontual, não contribuindo para o processo efetivo de ensino e aprendizagem e, em última instância, para a formação integral do aluno". Verifica-se que esse instrumento avaliativo nem sempre consegue traduzir de forma numérica a maior ou menor proximidade do conhecimento adquirido. De acordo com Silva e Moradilo (2002), dependendo da forma como ocorre a avaliação, o conhecimento escolar pode se restringir a uma ciência dogmática necessária ao aprender a fazer, sendo esta, uma condição para que os cidadãos adaptados à ordem vigente consigam ingressar ao mercado profissional.

Dessa forma, metodologias avaliativas que contemplem um reflexo da aprendizagem dos discentes, indo muito além da atribuição de notas, são importantes por possibilitarem a ampliação de debates sobre propostas educacionais, tanto no ensino de Ciências quanto no das demais disciplinas.

O ensino de ciências no Ensino Fundamental é por natureza multidisciplinar, envolvendo diversas áreas e contextos sociais. A aprendizagem desses conteúdos pode 
contribuir para o desenvolvimento discente e para prepará-los para o Ensino Médio e/ou profissionalizante. O problema é que nem sempre os alunos têm a consciência plenamente desenvolvida sobre a relevância do conhecimento científico para o bem-estar individual, social e profissional (CRISÓSTIMO; KIEL, 2017).

Nesse sentido, surge a necessidade de encontrar mecanismos que possam despertar o interesse para o assunto a ser ministrado, e o lúdico tem demonstrado ser uma alternativa viável e com resultados satisfatórios para ser utilizado como estratégia didática no ensino de Ciências.

\section{METODOLOGIA}

A atividade foi desenvolvida com alunos do $8^{\circ}$ ano do Ensino Fundamental de uma escola pública no município de Coari, no estado do Amazonas. O método utilizado apresentou abordagem qualitativa com a inferência dos resultados obtida pela observação dos pesquisadores participantes e uso de um caderno de anotações para registros das atividades (LAKATOS; MARCONI, 2017).

A intervenção fez parte das atividades desenvolvidas pelos acadêmicos do curso de Ciências: Biologia e Química da Universidade Federal do Amazonas participantes do Programa Residência Pedagógica, núcleo Química, e contou com a participação de 133 alunos de 4 turmas de discentes do $8^{\circ}$ ano. Segundo Damiani et al. (2013, p. 1), a intervenção pedagógica pode ser definida como "uma pesquisa que envolve o planejamento e a implementação de interferências (mudanças, inovações pedagógicas) - destinadas a produzir avanços, melhorias, nos processos de aprendizagem dos sujeitos que delas participam”. Assim, para este trabalho, as metodologias utilizadas foram subdivididas em: a) aula expositiva dialogada para a revisão dos conteúdos; b) atividade lúdica e c) avaliação.

A aula teórica foi realizada no final do período letivo com todo o conteúdo ministrado no bimestre, contemplando os assuntos: cadeia alimentar e corpo humano. Como recurso didático foi utilizado slide (data show) e quadro branco. Durante toda a aula os discentes puderam realizar questionamentos e fazer comentários. A atividade durou 50 minutos em cada turma.

A atividade lúdica consistiu em três jogos: quiz, trilha lúdica e uma pirâmide alimentar. Cada turma foi dividida em 3 grupos e os critérios da avaliação foram: participação, comprometimento, conhecimento teórico e trabalho em grupo. Todos os critérios foram previamente informados aos participantes. As atividades realizadas ocorreram de forma simultânea, no formato de rodízio e tiveram duração de 100 minutos em cada turma. 
a) Quiz de Ciência: tratou-se de perguntas e respostas sobre o corpo humano (sistemas, órgãos, tecidos e células). O objetivo era tentar acertar o máximo de questões sorteadas e testar os conhecimentos de forma interativa e divertida. Cada pergunta valia 1 ponto e cada questão era objetiva e de múltipla escolha, com 4 opções.

b) Trilha do conhecimento: foi um jogo idealizado para trabalhar temas ligados ao corpo humano, com a mesma temática que o Quiz. O material pedagógico foi composto por uma estrutura produzida em TNT, contendo casas com números produzidos com papel emborrachado, um dado produzido com papelão e cartas com informações do conteúdo abordado. Para jogar, o participante jogava o dado e se acertasse a questão, andava o número de casas correspondente ao dado. Em cada casa da trilha, havia cartas abaixo dos números com questões. O jogador deveria responder a uma pergunta relacionada ao tema da casa selecionada e virava a carta para ver se sua resposta estava correta. Respondendo corretamente, o estudante jogava novamente e quando errava, passava a vez. Ganhava o jogo o grupo que chegasse ao final da trilha primeiro.

c) Pirâmide dos alimentos: a atividade referia-se aos grupos alimentares e a importância da alimentação saudável. O material foi composto por 3 cartolinas de forma triangular. O jogo seguiu da seguinte forma: os alunos foram divididos em grupos de 3 e, para cada um, foi entregue uma cartolina com a estrutura da pirâmide alimentar. Como desenvolvimento, os estudantes deveriam colocar as figuras dos alimentos no local adequado, e em seguida, falar qual o benefício e o malefício daquele alimento. $\mathrm{O}$ grupo que terminasse primeiro de estruturar a pirâmide e que explicasse de forma adequada ganhava o jogo.

\section{RESULTADOS E DISCUSSÃO}

Sabe-se que o termo "avaliação" é comumente descrito pelos alunos como algo que deveria ser evitado e que remete a uma sensação de desconforto pelos discentes (OLIVEIRA; BARROSO; HOLANDA, 2020). Assim, este projeto buscou apresentar uma forma diferenciada de realizar a avaliação bimestral, utilizando a ludicidade para demonstrar a importância da avaliação e do conhecimento dos conteúdos didáticos de uma forma leve e motivadora. Crisóstimo e Kiel (2017) afirmam que o lúdico colabora com as "competências de aprender a ser, conviver, a conhecer, a fazer e desenvolver, aceitando as perdas e explorando a criatividade, atenção, concentração e socialização" 
$\mathrm{Na}$ aula teórica, os alunos demonstraram ter assimilado os conteúdos do bimestre ministrados nas aulas anteriores pela professora da disciplina de Ciências. Durante a revisão, alguns alunos foram mais participativos, interagindo e fazendo perguntas, enquanto outros eram mais tímidos e pouco participativos. Mediante isso, buscou-se envolver todos os discentes explicando as dúvidas que surgiam e contextualizando com situações cotidianas.

Na sequência da intervenção, foram realizadas as atividades lúdicas. Todos os jogos foram elaborados pelos residentes e as atividades realizadas podem ser visualizadas na Figura1

Figura 1 - Atividades lúdicas. A) Pirâmide e B) Trilha.
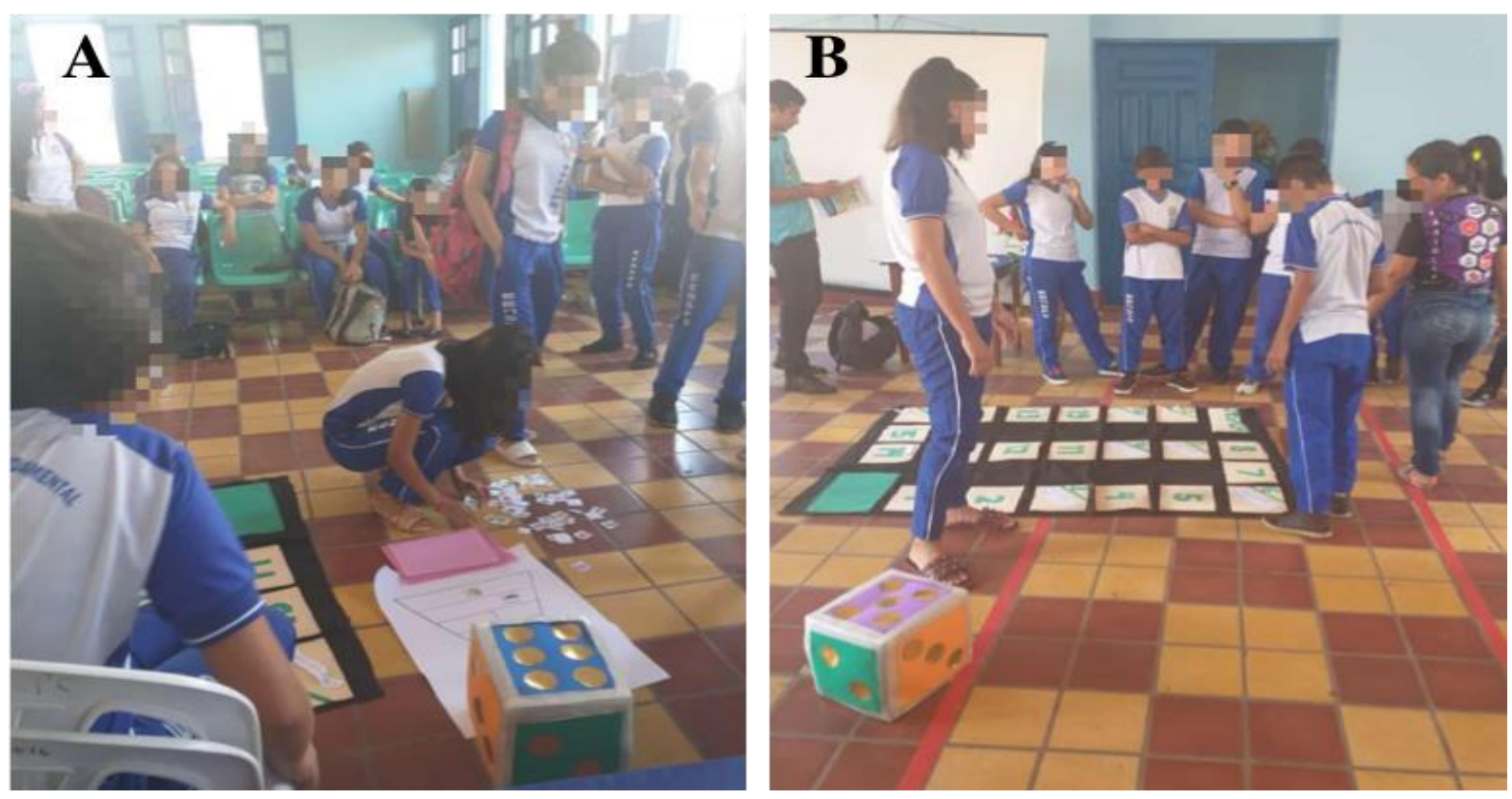

Fonte: arquivos da pesquisa, 2019.

Observou-se o interesse dos discentes, em que todos tiveram a oportunidade de demonstrar o conhecimento obtido. No jogo da trilha, apesar de apenas um de cada grupo ter sido escolhido para ser o marcador de localização (representante), os componentes do grupo participaram contribuindo com as respostas das questões. Observou-se que os discentes entenderem a necessidade do trabalho em grupo, da liderança, da troca de saberes e do respeito.

No jogo da pirâmide alimentar, um participante era escolhido pelo próprio grupo para atuar diretamente montando a pirâmide, e os demais orientavam sobre a posição correta dos alimentos e as características nutricionais de ingestão e consumo diário. Com isso, os alunos puderam relembrar como selecionavam os alimentos para uma alimentação saudável e os alimentos que deveriam ser ingeridos com precaução e limite. Esse foi o jogo mais agitado devido à necessidade de as peças serem organizadas de forma correta, necessitando de agilidade e conhecimento.

No jogo "Quiz da Ciência", todos do grupo puderam responder ao menos uma pergunta 
de forma individual, e os demais auxiliaram nas respostas. Como contribuição, os assuntos abordaram as formas de conhecer o organismo humano e seu funcionamento.

As perguntas do Quiz foram classificadas em fácil, moderada, difícil e muito difícil. Observou-se um grande número de acertos distribuídos uniformemente em cada nível de dificuldade (Figura 2). Esse resultado pode ser reflexo do interesse e da aprendizagem dos discentes relacionados aos conteúdos ministrados durante o bimestre. Sabe-se que os resultados detectados não são méritos apenas das atividades lúdicas, tendo em vista que essa foi a culminância, mas de um conjunto de fatores que contemplam as aulas ministradas pela docente responsável pela disciplina, a aula de revisão, a busca ativa dos alunos pelo conhecimento e a motivação deles em querer aprender.

Figura 2 - Número de acertos das 26 questões disponíveis no Quiz da Ciência

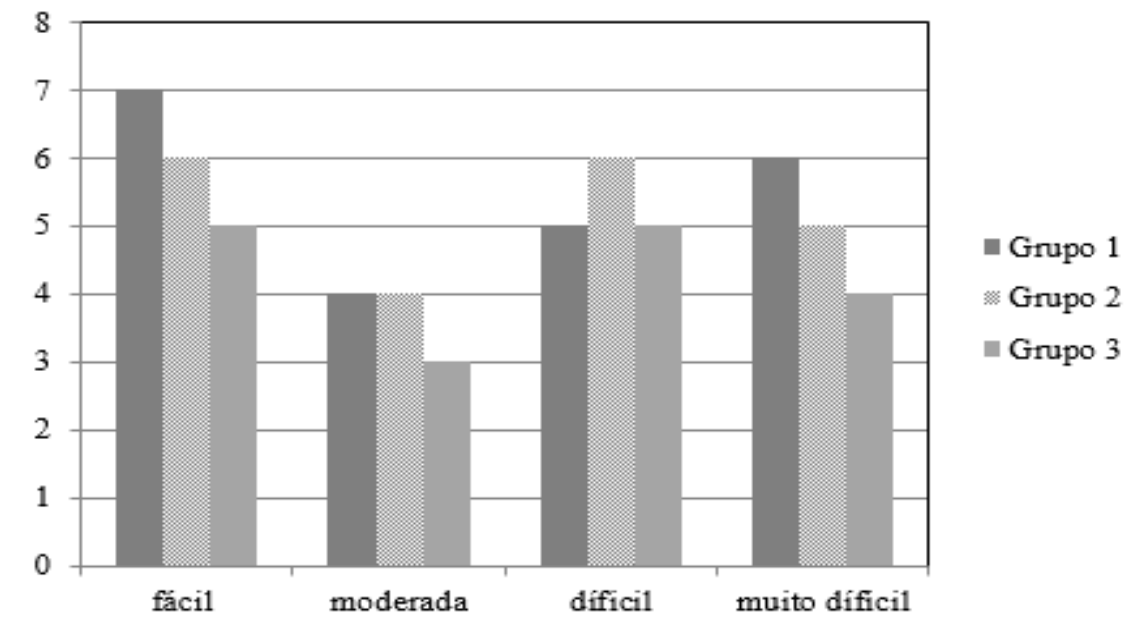

Fonte: dados da pesquisa

As 26 questões estavam subdividas, de acordo com o nível de dificuldade em "fácil" (07 questões), "moderado" (06 questões), “difícil” (07 questões) e "muito difícil”" (06 questões).

Além das regras gerais, os alunos estavam bem descontraídos em grupo, sem a pressão de uma prova convencional individual. Percebeu-se que houve preparação prévia dos discentes, tendo como consequência uma maior facilidade em responder as questões. Poucos aparentavam não ter estudado o assunto ou não ter prestado atenção na aula de revisão.

As perguntas selecionadas para os três jogos foram baseadas nas aulas e no livro didático utilizado pela escola no período de atuação do projeto, relacionadas ao corpo humano e à alimentação. Ambos os conteúdos foram ministrados durante o bimestre letivo. Segundo Cunha (2012), o conteúdo que se pretende ensinar deve estar fundamentado no conhecimento do discente, para que ocorra uma verdadeira assimilação, pela relação do conteúdo atual com o anterior. 
Os discentes ficaram concentrados nas atividades, com momentos de descontração que se constituiu na própria natureza da ludicidade, envolvendo respeito com a outra equipe e comprometimento. A liderança e o trabalho em equipe foram avaliados por observação dos participantes, pelos residentes e pelo acompanhamento da professora da disciplina.

Os alunos realmente se interessaram em participar das três atividades propostas, sendo motivados pelo desejo de vencer a competição e obter as maiores pontuações, bem como, de demonstrar conhecimento sobre o assunto para os demais componentes do grupo e da turma (autoafirmação).

Além disso, cita-se a importância do conteúdo utilizado como tema norteador. Segundo Mendes et al. (2019) e Lima et al. (2019), a conscientização do hábito da alimentação saudável nas escolas é uma estratégia para minimizar os elevados índices de obesidade infantil e doenças infanto-juvenis em consequência da má alimentação. Nos trabalhos citados, os autores utilizaram a ludicidade para demostrar a importância da alimentação para discentes do Ensino Fundamental.

Corroborando com os achados desta pesquisa, Stochero et al. (2019) utilizaram o lúdico e a contextualização como instrumentos de aprendizagem para auxiliar os alunos do quinto ano (Ensino Fundamental) a relacionarem os hábitos alimentares e as escolhas que fazem em seu cotidiano com o ensino de Ciências. Segundo os autores, a abordagem lúdica fez com que os alunos entendessem a importância da nutrição adequada e conseguiram identificar em sua própria alimentação o que poderia ser melhorado.

Para Crisostimo e Kiel (2017), as atividades lúdicas são mais interessantes para os alunos do que os habituais exercícios massivos, não se restringindo apenas ao ato de brincar, mas estando intrinsecamente correlacionado com o conhecimento científico.

Para minimizar qualquer sentimento estigmatizante, os alunos foram avaliados pelos critérios independentes do resultado da competição, que possuía como prêmio para os que conseguiram a maior pontuação, uma caixa de chocolate apenas para fomentar o desejo de participação. Como afirma Honoro e Oliveira (2016), a avaliação deve ser elaborada visando minimizar injustiças e incongruências que já possam ter ocorridos em avaliações anteriores, visando fortalecer a autoconfiança e o reflexo da aprendizagem.

Ainda nesse sentido, observou-se que a possibilidade de errar e prejudicar o grupo desencadeou um senso de responsabilidade e uma necessidade de estudar o assunto, ambas situações descritas de forma informal pelos adolescentes participantes. O mais interessante foi observar o grau de comprometimento em ler a questão e interpretá-la corretamente, comparando as alternativas em grupo e tentando encontrar a que era mais coerente com o conhecimento que eles tinham assimilado.

O que se observa é que em uma avaliação lúdica, tendo sido previamente informados os 
seus critérios para o grupo a que lhes será submetido, desencadeia-se um comportamento positivo na busca de superação das potencialidades individuais em prol do grupo.

Ainda se observou que os grupos que eram superestimados pelos demais grupos, por conterem alguns dos alunos que se saíram melhor nas avaliações individuais, na maior parte das vezes não ganharam a competição. Entre os diversos fatores que podem ter afetado esse resultado, uma explicação é que os demais alunos se empenharam muito acima do comum, e desenvolveram uma maior habilidade em grupo de relações humanas e sociais.

Ressalta-se também que, em algumas turmas, a liderança era alternada, dependendo da necessidade do grupo em relação ao conteúdo que era abordado. Assumia a liderança o discente que o grupo considerava mais apto. Nesse sentido, a avaliação demonstra não somente uma assimilação individual do conhecimento, mas um trabalho cooperativo de transmissão de saberes. O uso do critério de comprometimento também foi importante, pois fez com que os alunos se dedicassem por saberem que não seria apenas um jogo, e sim uma a avaliação, onde além de obter conhecimento teórico, haveria necessidade de participar e demonstrar a assimilação dos saberes.

Para Silva e Moradillo (2002), a avaliação escolar deve ser utilizada como um componente do processo educativo, visando orientar o ensino e facilitar a aprendizagem dos discentes. Para tanto, precisa ser utilizada como um ato colaborativo entre professores e alunos na busca de um aprimoramento compartilhado.

$\mathrm{Na}$ pesquisa realizada por Alípio e Galieta (2018), foram utilizadas metodologias diferenciadas como uso de vídeos, construção de modelos didáticos, participação em um dia letivo temático, além de prova escrita como avaliação. As autoras constataram que mesmo com o planejamento do uso de diferentes formas avaliativas, os discentes ainda reconhecem essas novas possibilidades como complementares à prova escrita, demonstrando o modelo tradicional enraizado na percepção deles.

Corroborando, Oliveira, Barroso e Holanda (2020) afirmam que se faz necessário que alternativas sejam criadas para minimizar o distanciamento do que é ensinado e da vivência discente, levando em consideração o cotidiano da escola, estudantes e professores, e buscando favorecer a cultura de investigação e diálogo, contribuindo assim, para a educação de qualidade.

Os resultados obtidos evidenciam que há diversas possibilidades a serem utilizadas para avaliar o conhecimento dos discentes, seja substituindo o modelo tradicional classificatório ou como forma complementar de investigar o quanto o ensino está sendo significativo para os discentes. Com isso, estimula-se a continuação das pesquisas sobre a avaliação e reflexões e debates do uso de atividades lúdicas no ensino de Ciências. Sabe-se que a busca pelo 
desenvolvimento e construção da aprendizagem de qualidade é algo constante e espera-se com esses resultados fomentar pesquisas na área.

\section{CONSIDERAÇÕES FINAIS}

A atividade de intervenção lúdica avaliativa demonstrou ser efetiva para analisar a assimilação dos conteúdos de Ciências, bem como de habilidades necessárias como liderança, trabalho em equipe e comprometimento dos participantes. O lúdico demonstrou ser um método interessante para ser utilizado como ferramenta de ensino e de aprendizagem no Ensino Fundamental por proporcionar momentos de entretenimento e descontração aliados à busca pelo aprimoramento de saberes. Os discentes demonstraram comprometimento e interesse em todas as atividades realizadas.

Este estudo reflete a necessidade de se abrir um maior espaço para atividades diferenciadas no ensino básico, sendo mais do que uma atividade complementar, demonstrando ser eficiente para ser utilizada como estratégia de habilitações que vão além do aspecto escolar, incluindo o social, profissional e pessoal dos estudantes

\section{Agradecimentos}

Os autores agradecem a todos os envolvidos, em especial à Professora Supervisora Jorcilene Souza, à Gestora Sirce Maria, à CAPES pelo Programa Residência Pedagógica e pelas bolsas concedidas aos residentes.

\section{REFERÊNCIAS}

ALÍPIO, Ana Carla Nascimento; GALIETA, Tatiana. Os diferentes processos avaliativos no ensino de ciências: quais são as interpretações dos alunos? Revista Brasileira de Ensino de Ciência e Tecnologia, vol. 11, n. 1, p. 50-72, 2018. Disponível em: https://periodicos.utfpr.edu.br/rbect/article/view/4747. Acesso em: 12 abr. 2020.

AUSUBEL, David Paul. A aprendizagem significativa: a teoria de David Ausubel. São Paulo: Moraes, 1982.

BRASIL. BNCC - Base Nacional Comum Curricular: área de Ciências da natureza e suas tecnologias. 2018.

CHUEIRI, Mary Stela Ferreira. Concepções sobre a Avaliação Escolar. In: Estudos em Avaliação Educacional, vol. 19, n. 39, p. 49-64, 2008.

CRISÓSTIMO, Ana Lúcia; KIEL, Cristiane Aparecida. O lúdico e o ensino de Ciências: saberes do cotidiano, Guarapuava: Ed. da Unicentro, 2017.

CUNHA, Marcia Borin. Jogos no ensino de química: considerações teóricas para sua utilização em sala de aula. Química Nova na Escola, vol. 34, n. 2, p. 92-98, 2012. 
DAMIANI, Magda Floriana; ROCHEFORT, Renato Siqueira; CASTRO, Rafael Fonseca de; Marion Rodrigues DARIZ; PINHEIRO, Silvia Siqueira. Discutindo pesquisas do tipo intervenção pedagógica. Cadernos de Educação, vol. 45, p. 57-67, 2013. Disponível em: https://periodicos.ufpel.edu.br/ojs2/index.php/caduc/article/view/3822. Acesso em $13 \mathrm{dez}$. 2020.

FERRO, Bruno Rogerio; VIEL, Franciele Vanessa. A importância do lúdico nas séries iniciais do ensino fundamental. Revista Cientifica UNAR, vol. 18, p. 109-129, 2019. Disponível em: http://revistaunar.com.br/cientifica/documentos/vol18_n1_2019/9_A_IMPORTANCIA_DO LUDICO_NAS_SERIES_INICIAIS_DO_ENSINO_FUNDAMENTAL.pdf. Acesso em 13 dez. 2020.

HONORO, Francisca Amaro dos Santos; OLIVEIRA, Maria de Fátima Augusto. Avaliação na educação infantil. In: III CONEDU - CONGRESSO NACIONAL DE EDUCAÇÃO. Editora realize, Anais [...]. Natal, RN, 2016. Disponível em: https://www.editorarealize.com.br/editora/anais/conedu/2016/TRABALHO_EV056_MD1_S A17_ID5551_16082016194655.pdf. Acesso em: 15 out. 2020.

KISHIMOTO, Tizuko Morchida. O jogo e a Educação Infantil. In: Jogo, Brinquedo, Brincadeira e a Educação. 5 ed. São Paulo: Cortez, 2001.

LAKATOS, Eva Maria; MARCONI, Marina de Andrade. Metodologia do Trabalho Científico. 8 ed. São Paulo: Atlas, 2017.

LIMA, Ana Paula Santos; ILHA, Phillip Vilanova; SILVA, Rodrigo Couto Corrêa; SOARES, Félix Alexandre Antunes. Learning for Projects in Fundamental Teaching: strategy for understanding food pyramid. Research, Society and Development, vol.8, n.1, p.1-18, 2019. Disponível em: https://rsdjournal.org/index.php/rsd/article/view/636. Acesso em 13 dez. 2020

MENDES, Ana Nery Furlan; ROCHA, Sandra Mara S.; SALVADOR, Paula FORRECHI, Cinthia Ronconi. O Ensino da pirâmide alimentar e a construção do hábito saudável por meio do lúdico: um estudo de caso. Revista de Estudos e Pesquisas sobre Ensino Tecnológico, v. 5, n.11, p. 234-252, 2019. Disponível em:

https://sistemascmc.ifam.edu.br/educitec/index.php/educitec/article/view/775. Acesso em: 12 ago. 2020.

OLIVEIRA, Maria Elizete Pereira Alencar; BARROSO, Maria Cleide da Silva; HOLANDA, Francisca Helena de Oliveira. Science teaching in basic education: student learning and teacher practice from the perspective of evaluations. Research, Society and Development, vol. 9, n.7, p.1-12, 2020. Disponível em: https://rsdjournal.org/index.php/rsd/article/view/3500. Acesso em 13 dez. 2020.

PAIS, Heloisa Mirian V.; SILVA, Regivalda C. de Souza; SOUZA, Simone M. de Souza; FERREIRA, Anna Rebeka Oliveira Ferreira; MACHADO, Márcio Fraiberg. A contribuição da ludicidade no ensino de ciências para o ensino fundamental. Brazilian Journal of Development, Curitiba, vol. 5, n. 2, p. 1024-1035, 2019.

REZENDE, Flávia. As novas tecnologias na prática pedagógica sob a perspectiva construtivista. Revista Ensaio, vol. 2, n. 1, p.70-87, 2002. 
SILVA, José Luís Paula Barros; MORADILLO, Edilson Fortuna. Avaliação, ensino e aprendizagem de ciências. Ensaio Pesquisa em Educação em Ciências, vol.4, n.1, p. 1-12, 2002. Disponível em: https://www.scielo.br/pdf/epec/v4n1/1983-2117-epec-4-01-00028.pdf. Acesso em ago. 2020.

SOARES, Márlon Hebert Flora Barbosa. Jogos e atividades lúdicas no ensino de química: uma discussão necessária para novos avanços. REDEQUIM, vol. 2, n. 2, p. 5-13, 2016. Disponível em: http://www.journals.ufrpe.br/index.php/REDEQUIM/article/view/1311. Acesso em 13 ago. 2020.

STOCHERO, Emanuelle; GARCEZ, Tatiane Fontoura; CORREAA, Debora Muller; COELHO, Franciele Braz de Oliveira. O uso do modelo didático pirâmide alimentar na aprendizagem dos princípios de uma alimentação saudável. In: SALÃO INTERNACIONAL DE ENSINO, PESQUISA E EXTENSÃO. Anais [...], Unipampa, 2019. Disponível em:

https://periodicos.unipampa.edu.br/index.php/SIEPE/article/view/87972. Acesso em $13 \mathrm{dez}$. 2020.

VIGOTSKI, Liev Semionovich. Psicologia pedagógica. Edição comentada. Porto Alegre: Artmed, 2003.

YAKAMOTO, Maria Emília. VALENTOSA, Jaroslava Varella. Manual de Psicologia Evolucionista. Natal: Edufrn, 2918.

\section{SOBRE OS AUTORES}

Klenicy Kazumy de Lima Yamaguchi é doutora, mestre e graduada em Química. Professora Adjunta no Instituto de Saúde e Biotecnologia da Universidade Federal do Amazonas.

E-mail: klenicy@gmail.com

ORCID: http://orcid.org/0000-0001-7998-410X

Bianca Ferreira Neves é graduanda em Ciências: Biologia e Química no Instituto de Saúde e Biotecnologia da Universidade Federal do Amazonas.

E-mail: bianca_campusufam@hotmail.com

ORCID: http://orcid.org/0000-0002-7429-1491

Felipe Lourenço Albuquerque é graduando em Ciências: Biologia e Química no Instituto de Saúde e Biotecnologia da Universidade Federal do Amazonas.

E-mail: felipe.secretario@gmail.com

ORCID: http://orcid.org/0000-0003-0850-6164

Recebido em 12 de agosto de 2020. Aprovado em 27 de novembro de 2020. Publicado em 23 de dezembro de 2020. 